\title{
APUNTES HISTÓRICOS DE LA FACULTAD DE DERECHO DE GRANADA EN EL HORIZONTE DE SU V CENTENARIO'.
}

\author{
Alejandro Martínez Dhier \\ Profesor Titular de Historia del Derecho, \\ Universidad de Granada. \\ Correo electrónico: amdhier@ugr.es
}

RESUMEN: El presente artículo que sintetizamos en estas líneas, traza un recorrido histórico de la Facultad de Derecho de la Universidad de Granada, desde su creación, en el primer tercio del siglo XVI, hasta la actualidad, abordando algunas cuestiones fundamentales relacionadas con los estudios jurídicos, y sus planes de estudios, y algunos de sus protagonistas principales, como docentes y como estudiantes, figuras insignes de la ciencia jurídica y de la cultura, en general, de nuestro país. Próximos al V Centenario de su fundación, es un buen momento para reflexionar sobre la casi cinco veces centenaria institución granadina, máxime cuando aún no contamos con un estudio histórico-jurídico completo sobre la Facultad de Derecho granadina.

PALABRAS CLAVE: Historia, Facultad de Derecho, Universidad de Granada, estudios jurídicos, Planes de Estudio, juristas.

\begin{abstract}
ABSTRAT: The paper tries to make a historical view of the Law Faculty of the University of Granada from its born, at the first third of the 16th century, until today. The main of the research is to study some of the fundamental questions related to Law studies and theirs syllabus, some of their main actors such as relevant professors and students which were a relevant person in the law science, culture, and life of the country. Close to the Vth century anniversary, it is a perfect time to make some comments of the classical university institution, particularly when there is no full historical research about the Granada Law Faculty from a law point of view.
\end{abstract}

KEYWORDS: History, Law Faculty, University of Granada, law studies, Syllabus, Layers.

Recibido el 18/10/2016 y aceptado el 28/11/2016

\footnotetext{
${ }^{1}$ Proyecto de Investigación PRY113/14 del Centro de Estudios Andaluces: "El papel de las Facultades de Derecho, de las Universidades de Andalucía, durante la época de la transición política española (19761981)”. Investigador principal: Alejandro Martínez Dhier (Universidad de Granada).
} 
SUMARIO: 1 . Introducción. 2. Origen y establecimiento de los estudios jurídicos en la Universidad de Granada. 3. Los estudios jurídicos en la Universidad de Granada. 3.1. El Plan de Estudios de 1776. 3. 2. Proyecto sobre reforma de los Estudios de la Facultad de Derecho de 1883. 3.3. El Plan de Estudios de 1953. 3.4. El Plan de Estudios de 2000. 3.5. El Grado en Derecho: ¿E.E.E.S.? 4. Protagonistas en la Historia de la Facultad de Derecho de Granada: los juristas.

\section{INTRODUCCIÓN.}

La historia de la Facultad de Derecho de la Universidad de Granada está aún por hacer; otras Facultades de Derecho de nuestro país, sí tienen su historia: Valencia, Sevilla, Salamanca, Oviedo, Alcalá de Henares, o, entre otras, Madrid (Complutense, o Carlos III), cuentan con valiosas aportaciones.

La Universidad como institución, una de las más sensibles de las instituciones sociales, es producto de un largo devenir histórico, y su evolución se encuentra íntimamente ligada a la de la sociedad en la que se encuentra, ocupando las Facultades de Derecho desde antiguo, el eje central de todo el sistema estructural universitario ${ }^{2}$.

Hoy en día, los estudios universitarios han sufrido un profundo cambio con la llegada del Espacio Europeo de Educación Superior, y los Grados universitarios ${ }^{3}$, pero ya ha llegado el momento de mirar hacia atrás, y de reconstruir la historia de la Facultad de Derecho de la Universidad de Granada, que cuenta, es cierto, con apreciables aportaciones científicas, aunque parciales en su completo devenir histórico.

Próximos al quinto centenario de la Universidad de Granada, la Facultad de Derecho no puede quedarse atrás en esta histórica cita, pues los estudios jurídicos son consustanciales a la creación misma en 1526-1531 del Estudio General granadino.

\footnotetext{
${ }^{2}$ ORLANDIS, J., La crisis de la Universidad en España, Madrid, 1966, págs. 11-12: “crisis quiere decir simplemente transformación, cambio profundo, revisión a fondo de viejos moldes y estructuras, y bajo este concepto es perfectamente lícito hablar de crisis; más aún, lo alarmante sería que esa crisis no existiera, porque significaría que la Universidad había perdido el pulso y no marchaba ya al ritmo de la sociedad contemporánea".

${ }^{3}$ La definición que de "Universidad" da el Diccionario de la Real Academia recoge las dos acepciones históricas: "Universidad" y "Estudio General"; así, "institución de enseñanza superior que comprende diversas facultades, y que confiere los grados académicos correspondientes. Según las épocas y países puede comprender colegios, institutos, departamentos, centros de investigación, escuelas profesionales,...", y "edificio o conjunto de edificios destinados a las cátedras y oficinas de una Universidad” (REAL ACADEMIA ESPAÑOLA, Diccionario de la lengua española, Madrid, 23 ed., ed. del tricentenario, 2014, pág. 2197).
} 
2. ORIGEN Y ESTABLECIMIENTO DE LOS ESTUdios JURídicos EN LA

\section{UNIVERSIDAD DE GRANADA.}

La Universidad de Granada es creada por Real Cédula de 7 de diciembre de 1526 de Carlos V dirigida al arzobispo Pedro Ramiro de Alba ${ }^{4}$ : Ad Fugandas in fidelium tenebras, haec domus literaria fundata est, un "Estudio General” de Lógica, Filosofía, Teología, Cánones, Gramática y casos de conciencia 5 .

Años más tarde, el 14 de julio de 1531, recibe la Bula fundacional de Clemente VII, otorgándole idénticas prerrogativas y privilegios que a las Universidades de Bolonia, París, Salamanca y Alcalá de Henares, y nombrando al arzobispo de Granada "protector y administrador" de la misma, quien un año más tarde nombraría a Jorge de Torres como primer Rector ${ }^{6}$; tiene, pues, la Universidad de Granada una doble fundación: imperial y pontificia:

«En Granada, en los palacios arzobispales, a diez e nueve días del ano del Senor de mill e quinientos e treynta e dos anos, el reuerendísimo senor don Gaspar de Áualos, arçobispo de Granada, del Consejo de su magestad y administrador perpetuo de la Vniuersidad que agora nuevamente ha er[egido] e creado en esta çibdad nuestro muy santo padre Clemente septimo a suplica[çion] del Emperador y Rey, nuestro señor, e de su señoría reuerendísima como paresçe todo por las bullas de la dicha ereçion e creaçion de Vniuersidad, dixo que por quanto estava bien ynformado por esperiençia y por relaçion de las muchas personas fidedignas de las letras y méritos de los venerables maestros Juan Clemente y Miguel de la Gasca y Françisco Ortiz que

\footnotetext{
${ }^{4}$ Memoria del estado de la enseñanza en la Universidad de Granada y establecimientos del distrito de la misma, en el curso de 1858 á 1859, y anuario para el de 1859 á 1860, conforme á los artículos 29 y 36 del Reglamento General Administrativo, y á la Orden de la Dirección General de Instrucción Pública, de 4 de noviembre de 1859, Granada, Imprenta de Francisco Ventura y Sábatel, 1860, esp. págs. 5-7, disponible digitalmente: digibug.ugr.es/bitstream/10481/19279/1/C-039-193(1).pdf (consulta de 20 de octubre de 2016). CALERO PALACIOS, $\mathrm{M}^{\mathrm{a}}$ del C., "La creación de la Universidad", Carlos V, Quinto Centenario, disponible digitalmente: http://canales.ideal.es/especiales/carlosV/creacion_universidad.html (consulta de 21 de octubre de 2016).
}

${ }^{5}$ El Código de las Siete Partidas: «Estudio es ayuntamiento de maestros e de escolares, que es fecho en algún logar, con voluntas e entendimiento de aprender los saberes. E son dos maneras dél: la una es a que dicen, Estudio General, en que ha maestros de las Artes, asi como de gramática, é de lógica, é de aritmética, é de geometría, é de astrología; é otrosí en que ha maestros de decretos é de señores de leyes. E este estudios debe ser establecido por mandato del Papa, ó del Emperador, ó del Rey. La segunda manera es a que dicen: Estudio particular, que quiere tanto decir como cuando algún maestro muestra en alguna villa apartadamente a pocos escolares. E tal como este pueden mandar hacer perlado ó concejo de algún logar» (Glosadas por el Licenciado Gregorio López, Salamanca, 1555, edición facsímil, editorial BOE).

${ }^{6}$ LÓPEZ, M. Á., Los Rectores y Cancilleres de la Universidad de Granada (1532-2004), Granada, Editorial Universidad de Granada, 2006, pág. 51. 
han regentado en esta çibdad y que sus personas serían muy provechosas para esta nueva Vniversidad, e h[a]rían en ella con su dotrina mucho provecho e se honrraría con ellos que por la auctoridad apostólica de que vsava, los yncorporava e yncorporó en esta Vniversidad para que de aquí adelante fuesen mienbros e hijos ella, e les dio poder e facultad para que pudiese cada vno dellos [dar] el grado de bachiller a cada vno de sus discípulos aviendo hecho el curso que se requiere e [...] reçebirle segund la costunbre de Alcalá, no obstante que algund [...] curso no oviese avn Vniversidad en esta çibdad, porque en esto [...] qualesquier defectos y cosas que obstasen. Con tanto que en ellos oviesen [...] y quiso que asy los dichos maestros nuevamente yncorporados en esta nueva Vniversidad, como los dichos sus discípulos gozasen de las preheminençias e prerrogativas que suelen e deven gozar los maestros y estudiantes de las Vniversidades de Salamanca e Valladolid e Alcalá e París e Bolonia, como lo dize la bulla de la ereçión desta dicha Vniversidad. Lo qual todo que dicho es hizo su señoría reuerendísima ante mí Juan de Valdés, su secretario e notario de la dicha Vniversidad, y fueron testigos a ello presentes: don Jorge de Torres, maestrescuela y el liçençiado Françisco de Vtiel, canónigo e provisor, y el liçençiado Estevan Nuñez, canónigo asy mismo en esta yglesia de Granada» ${ }^{7}$.

La creación de la institución universitaria granatensis era así un ejemplo más de la intensa "vida intelectual y cultural de la España del Renacimiento", unida al profundo sentimiento religioso que caracterizaba a la política del propio Emperador ${ }^{8}$, estando presente desde el inicio de su creación los estudios jurídicos 9 .

\footnotetext{
${ }^{7}$ MORENO TRUJILlO, M. ${ }^{\text {a }}$ A. y DE LA OBRA SIERRA, J. M. ${ }^{\text {a }, ~ " E l ~ p r i m e r ~ L i b r o ~ d e ~ A c t a s ~ d e ~ C l a u s t r o ~}$ y Grado de la Universidad de Granada. Edición y transcripción" en Primer Libro de Actas y Claustro y Grados de la Universidad de Granada (1532-1560), Granada, Universidad de Granada, 2007, págs. 6566.

8 "Resumen histórico (del estudio inédito de los Profesores OROZCO DIAZ y BERMÚDEZ PAREJA)", en Universidad de Granada. Guía de la Universidad 1979, Granada, Servicio de Publicaciones de la Universidad de Granada, 1979, esp. págs. 5-6: "La idea que preside esta fundación puede decirse que arranca de la Junta de Obispos y Letrados que, para resolver los problemas planteados por los moriscos, convocó Carlos V en 1526, durante su estancia en Granada, y que se celebró en la recién erigida Capilla Real, bajo la presidencia de don Alonso Manrique, Arzobispo de Sevilla. Recordemos cómo se concentraba esta aspiración universitaria bajo las bóvedas del primer templo de España que dio cobijo al arte renacentista, precisamente, en los mismos días que en los jardines de la Alhambra o del Generalife, con la aprobación de Garcilaso, decidían la introducción en nuestra poesía de los musicales versos italianizantes. Granada, la ciudad musulmana sin el peso de la tradición medieval cristiana, se abría gozosa a los nuevos y claros aires renacentistas, incorporándose de una vez a la vida intelectual artística y literaria del Occidente europeo".
}

9 ARIAS DE SAAVEDRA, I., "Estudio Preliminar" en El Plan de Estudios de la Universidad de Granada en 1776, edición facsímil, Granada, Universidad de Granada, 1996, esp. págs. xx-xxi: “Con un profesorado formado en la Universidad de Alcalá y un alumnado mayoritario del reino de Granada, o de zonas limítrofes, la Universidad de Granada comenzó impartiendo estudios de Filosofía, Teología, Leyes, Cánones y Medicina, aunque los estudios de Teología y Cánones eran, como en el resto de las universidades españolas, los de mayor protagonismo. Este rasgo en el caso granadino se acentuó por las propias condiciones de su fundación. La Universidad de Granada fue creada como un centro de formación del clero que había de llevar a cabo la evangelización de los moriscos”. 
En Granada ya estaban erigidos los Colegios de San Cecilio ${ }^{10}$, San Miguel ${ }^{11}$, Santa Catalina mártir" ${ }^{12}$, Santa Cruz de la $\mathrm{Fe}^{13}$, germen del propio "Estudio General granadino"14, y más adelante, el Seminario Conciliar San Dionisio Areopagita del Sacromonte de Granada ${ }^{15}$; estos Colegios, junto al de San Jerónimo, San Bartolomé y

Al respecto, PESET, M., y ALONSO ROMERO, M. ${ }^{a}$ P., "Las Facultades de Leyes", Historia de la Universidad de Salamanca, III.1, Saberes y confluencias, Salamanca, 2006, pags. 21-73.

${ }^{10}$ MARTÍN HERNÁNDEZ, F., Un seminario español pretridentino, el Real Colegio Eclesiástico de San Cecilio de Granada (1492-1842), Valladolid, Universidad de Valladolid, 1960.

${ }^{11}$ Real Cédula de S. M. y Señores de su Real Cámara de Castilla, por la que se aprueban y confirman los Mandatos, que para el mejor régimen, y gobierno del Imperial Colegio de San Miguel de esta ciudad formó el Sr. Don Pedro Dávila Cárdenas, del Consejo de S. M. su Oidor en la Real Chancillería de esta Corte, en la visita, que en virtud de Orden de dicho Supremo Tribunal practicó al referido Colegio, Granada, Imprenta de los Herederos de Don Bernardo Torrubia, 1774, disponible digitalmente en: http://adrastea.ugr.es/tmp/_webpac2 1103054.104001 (consulta de 11 de septiembre de 2012). CABRERIZO, J. A. (transcripción de), Documentos inéditos para la Historia de Granada: "Minuta de la contestación que dio el Arzobispo de Granada, D. Pedro de Castro, a una R. C. de Felipe II. Dá cuenta de los centros docentes que había en Granada, rentas de que vivían y causas por qué no fundó el Seminario, conforme al Concilio de Trento" (del Archivo Secreto del Sacromonte de Granada. leg. 1, parte 1. ${ }^{\text {a }}{ }^{\text {o }}$ 318), en Revista del Centro de Estudios Históricos de Granada y su Reino, año XIII, núm. 1 y 2, Granada, Tipografía de El Defensor, 1923, págs. 95-96 (disponible digitalmente en: http:// www.granada.cehgr.es/images/stories/revistas/1923\%20-\%20Tomo\%2013.pdf, consulta de 12 de octubre de 2016).

${ }^{12}$ Instituido por el Arzobispo Gaspar de Ávalos en 1537; vid. LÓPEZ RODRÍGUEZ, M. Á., "El Colegio de Santa Catalina Mártir (Granada, 1537-1802)”, Archivo Teológico Granadino, 54 (1991), págs. 91-228; y CALERO PALACIOS, M. ${ }^{a}$ del C. - SÁNCHEZ MARÍN, J. A., El Colegio de Santa Catalina Mártir: estudio de sus constituciones. Texto latino y traducción, Granada, Universidad de Granada, 1997.

${ }^{13}$ Fundado por Carlos V en virtud de Cédula de 7 de noviembre de 1526; vid., LÓPEZ RODRÍGUEZ, M. Á., El Colegio Real de Santa Cruz de la Fe, Salamanca, Universidad de Salamanca, 1974; y JIMÉNEZ VELA, R. - MARTÍN VEGA, C., El fondo de Santa Cruz de la Fe y Santa Catalina Mártir: aplicación de la ISAD $(G)$ a su descripción, en Actas de las I Jornadas de Archivos Históricos en Granada, Granada, Diputación Provincial, Universidad de Granada, 1999, disponible digitalmente en: http://www.ugr.es/ archivo/files/jimenez.pdf (consulta de 21 de octubre de 2016).

\footnotetext{
${ }^{14} \mathrm{Al}$ respecto, ARIAS DE SAAVEDRA, I., "La Universidad de Granada en la Época Moderna. Estudio y estado de la cuestión, Miscelánea Alfonso IX, 2007. Universidades hispánicas. Modelos territoriales en la Edad Moderna, II: Valencia, Valladolid, Oñate, Oviedo y Granada, Salamanca, Centro de Historia Universitaria Alfonso IX, Universidad de Salamanca, 2008, págs. 237-268.

Ya en pleno siglo XIX por disposición de Carlos IV, en una Real Cédula de 1802, se fusionó el Colegio de Santa Cruz de la Fe y el Colegio de Santa Catalina Mártir para constituir el Colegio de Santa Cruz de la Fe y Santa Catalina Mártir, albergando a teólogos y juristas y pasando a ocupar, físicamente, parte del edificio del Colegio de San Pablo, cedido a la Universidad tras la expulsión de los jesuitas, hasta su supresión acaecida tras la reforma de 1835.
}

${ }^{15}$ Establecido junto a la Abadía-Iglesia Colegial del Sacromonte en 1609 por Pedro Cabeza de Vaca de Castro y Quiñones en la ciudad nazarí, con la aprobación del pontífice Pablo V (20 de noviembre de 1609). Para ello, vid. MARTíNEZ DHIER, A., "Los estudios jurídicos en el Seminario Conciliar San Dionisio Areopagita del Sacromonte de Granada", Revista de Estudios Histórico-Jurídicos de la Escuela de Valparaíso (Chile), 35 (2013), págs. 347-416, disponible digitalmente: http://www.scielo.cl/pdf/rehj/n35/a11.pdf 


\section{Doctrina y Jurisprudencia}

Santiago $^{16}$, San Fernando y San Pablo ${ }^{17}$, completarán el mapa colegial granadino ${ }^{18}$, siguiendo así la doctrina del Concilio de Trento: ita ut hoc Collegium Dei ministrorum perfectum Seminarium sit ${ }^{19}$.

La ubicación de la Universidad de Granada se proyectó en un primer momento junto al monasterio de San Jerónimo, trasladándose finalmente junto a la Catedral, en el Colegio Mayor y Real de Santa Cruz de la Fe.

Con la expulsión en 1767 de los jesuitas se enclavó por Real Cédula de 26 de agosto de 1769, dada por Carlos III, en el Colegio de San Pablo -que comenzaría su actividad en 1583-, actual sede del edificio central de la Facultad de Derecho de Granada, situado en la plaza de la Universidad ${ }^{20}$.

\footnotetext{
${ }^{16}$ MARTÍNEZ LUMBRERAS, F., "Una fundación granadina. El primitivo Colegio de Santiago", Revista del Centro de Estudios Históricos de Granada y su Reino, año II, tomo II, núm. 4, Granada, Imp. de El Defensor de Granada, 1912, págs. 314-337 (disponible digitalmente en: http://www.granada.cehgr.es/images/stories/revistas/1912\%20-\%20Tomo\%202.pdf, consulta de 12 de octubre de 2016; y Una fundación granadina. Historia del Real Colegio de San Bartolomé y Santiago, Granada, $2^{a}$ ed., 1915; ORIOL CATENA, F., "El Real Colegio de San Bartolomé y Santiago", Anales de

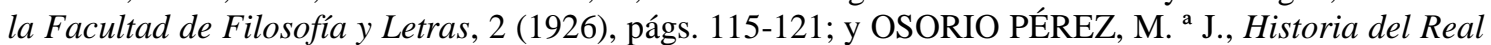
Colegio de San Bartolomé y Santiago, Granada, Universidad de Granada, 1987.

${ }^{17}$ OLIVARES, E., La docencia de filosofía y teología en el Colegio de San Pablo de Granada (15581767), Granada, 1989; Historia del Colegio de San Pablo, Granada, 1554-1765, transcripción de J. de BETHENCOURT y revisión y notas de E. OLIVARES, Granada, 1991; y MONTELLS Y NADAL, F. de P., Historia del origen y fundación de la Universidad de Granada, Granada, Imprenta de D. Indalecio Ventura, 1870, edición facsímil: Granada, Editorial Universidad de Granada, 2000, con "Estudio Preliminar" a cargo de Cristina VIÑES MILLET.
}

${ }^{18}$ Vid. ÁLVAREZ DE MORALES, A., La Ilustración y la reforma de la Universidad en la España del siglo XVIII, Madrid, Instituto Nacional de Administración Pública, 1988.

${ }^{19}$ Canones et decreta Sacrosancti oecumenici et generalis Concilii Tridentini sub Paulo III, Iulio III, Pio IIII Pontificibus Max, Compluti [Andreas de Angulo, 1564, reproducción digital en Biblioteca Virtual Miguel de Cervantes (http://bib.cervantesvirtual.com/FichaObra.html?Ref=11231), can. XVIII: De Reformatione, sessio (http://bib.cervantesvirtual.com/servlet/SirveObras/01372753133571620089024/ima0172.htm)]. Para un texto en castellano, véase: Biblioteca Electrónica Cristina: http://multimedios.org/docs/d000436/p000004.htm\#3-p0.11.1 (consulta de 20 de octubre de 2013).

${ }^{20}$ MARÍN OCETE, A., "Documentos históricos de la Universidad de Granada", Anales de la Facultad de Filosofía y Letras de la Universidad de Granada 1-2 (1925-1926), págs. 9-56 y 3-56, respectivamente; OROZCO DÍAZ, E. - BERMÚDEZ PAREJA, J., "La Universidad de Granada desde su fundación hasta la rebelión de los moriscos (1532-1568)", en Carlos V (1500-1558): Homenaje de la Universidad de Granada, Granada, Universidad de Granada, 1958, págs. 563-593; CAMACHO EVANGELISTA, F. (editor), Constituciones de la Universidad de Granada (1542), Granada, 1982; CALERO PALACIOS, M. ${ }^{a}$ del C., La Universidad de Granada. Los documentos fundacionales, Granada, Servicio de

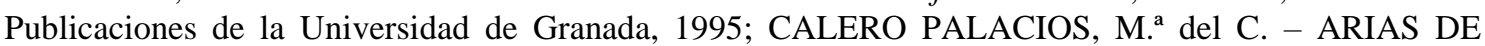
SAAVEDRA I. - VIÑES MILLET, C., Historia de la Universidad de Granada, Granada, Editorial Universidad de Granada, 1997; Historia del Colegio de San Pablo, Granada, 1554-1765, transcripción de J. de BETHENCOURT y revisión y notas de E. OLIVARES, Granada, 1991; y MONTELLS Y NADAL Francisco de Paula, Historia del origen y fundación de la Universidad de Granada, ya cit. 


\section{Doctrina y Jurisprudencia}

Con la llegada del siglo XIX, y su secularización ${ }^{21}$, y consiguiente supresión de los Colegios Universitarios, se ubicará la Universidad de Granada en su integridad en el Colegio de San Pablo 22 .

Este emplazamiento, tras sucesivas reformas, la más importante de 1841 para la construcción del actual Jardín Botánico, ya previsto en el Plan de Estudios de 1776 para los ejercicios de los respectivos estudiantes en la forma que se usa después de los últimos adelantamientos de las ciencias naturales ${ }^{23}{ }^{23}$, pasó a ser también sede de otros organismos e instituciones; el Claustro Javier de Burgos, inexistente en la primitiva construcción, albergó entonces dependencias militares, la Diputación Provincial de Granada, el entonces Gobierno Civil, y la Facultad de Ciencias.

Hasta 1980, con el traslado al Hospital Real ${ }^{24}$ cedido a la Universidad definitivamente diez años atrás, actual Rectorado, en el enclave de la Facultad de Derecho se habían encontrado tradicionalmente los servicios centrales de la Universidad: Rectorado, Biblioteca Universitaria General y los Servicios Centrales.

A partir de esa fecha, en el edificio del Colegio de San Pablo se ubicará el Decanato de la Facultad de Derecho, los distintos Departamentos y Áreas de Conocimiento, a raíz de su creación por la Ley de Reforma Universitaria, los servicios administrativos, así como algunas de las Aulas donde se imparte diariamente docencia, junto al Salón Rojo y Paraninfo, antiguo teatro para las diputationes de Teología y Filosofía, que conserva la bóveda de 1675, en el cual por una Real Orden de 26 de agosto de 1769 se permitirá celebrar actos públicos y académicos, y donde, entre otras “maravillas", se conserva un repostero de la II República descubierto durante las obras

\footnotetext{
${ }^{21}$ Para todo ello: GIL DE ZÁRATE, A., De la Instrucción Pública en España, Madrid, Imprenta del Colegio de Sordo-mudos, 3 tomos, 1855 (ed. facsímil, Oviedo, Pentalfa Ediciones, 1995), esp. pág. X: "La reorganización de la enseñanza tenía que ser completa, como lo había sido la reorganización política".

22 PALOMERO PÁRAMO, J. M., Patrimonio artístico y monumental de las Universidades andaluzas, Sevilla, 1992, esp. págs. 49-50.

23 Vid. FERNÁNDEZ-CARRIÓN M., GARCÍA MONTES, J. M., MOLERO MESA, J., El Jardín Botánico de la Universidad de Granada, Granada, 1993.

${ }^{24} \mathrm{Al}$ respecto, vid. VALENZUELA CANDELARIO, J., "El insigne y suntuoso Hospital Real de Granada (I). Las fundaciones reales y la reunión hospitalaria (1501-1526)", Dynamis: Acta hispanica ad medicinae scientiarumque historiam illustrandam 23 (2003), págs. 193-219, y "El insigne y suntuoso Hospital Real de Granada (II): oficiales y sirvientes en un hospital general (1526-1535)", Dynamis: Acta hispanica ad medicinae scientiarumque historiam illustrandam 24 (2004), págs. 213-241.
} 


\section{Doctrina y Jurisprudencia}

de restauración en el año 1998, oculto tras el retrato del Emperador que la fundó y que preside dicha Aula Magna, y caracterizado por una "corona murada".

La Facultad de Derecho cuenta también, como edificio central de docencia, con el Aulario de la Facultad de Derecho, así como la nueva Biblioteca de la Facultad de Derecho, en la sede histórica de la "Real Sociedad Económica de Amigos del País de la Provincia de Granada" (1776-1889).

\section{LOS ESTUDIOS JURÍDICOS EN LA UNIVERSIDAD DE GRANADA.}

\section{1. el Plan de Estudios de 1776.}

Del reinado de Carlos III data precisamente uno de los planes de estudios "más avanzados" de toda la Universidad española: por Real Provisión de 25 de noviembre de 1776, en el que debe ocupar un lugar destacado el insigne jurista granadino, y consejero de Castilla, Pedro José Pérez Valiente, suponiendo, en lo que al Derecho se refiere, la unificación en una sola Facultad de lo que antes eran dos Facultades de Leyes y Cánones (“Jurisprudencia Civil y Canónica”)", dotándose siete Cátedras para el estudio del Derecho, no sólo ya del Derecho Común romano-canónico, lo que hasta entonces primaba en las aulas, sino también del Derecho público y nacional:

- Primer año: Historia del Derecho Natural y Civil e Historia del Derecho Canónico.

- Segundo y tercer año: dos Cátedras de Instituta.

- Cuarto y quinto curso: Instituciones de Derecho Canónico, Derecho Eclesiástico nuevo -Decretales-y antiguo-Decreto de Graciano-.

\footnotetext{
${ }^{25}$ Real Provisión de su Magestad y señores del Consejo por la que se establece el numero de Catedras, y el método de enseñanzas y estudios que ha de haver desde su publicacion en la Real Universidad de Granada, Madrid, M.DCCLXXVI, fol. 16. v: "Haviendo un reciproco enlace entre el Sacerdocio y el Imperio, el Derecho del Estado y de la Iglesia, y no pudiendo ser perfecto Jurisconsulto el que no sepa el Derecho Canonico, ni buen Canonista el que carezca del fundamento del Derecho Civil y Real, es consiguiente deba caminar unido el estudio de estas Facultades, y que preceda en ambas á los grados mayores que se hayan de recibir en Derechos".
} 


\section{Doctrina y Jurisprudencia}

- Sexto años: Leyes del Reino conforme a las Recopilaciones de Castilla e Indias, con las Pragmáticas y Autos Acordados, y las Leyes de Toro Covarrubias y Antonio Gómez- .

- Y séptimo, y último año: estudio del Derecho público, civil y eclesiástico, y cuyo titular era el Prefecto de la Facultad ${ }^{26}$.

Hoy en día las Facultades de Derecho procuran una formación amplia del alumno que incremente su bagaje cultural, enriquezca su entendimiento y su capacidad de razonar y fomente su sentido de la lógica y la crítica; adquirir la información, racionalizarla, analizarla y criticarla son tareas que proporcionan una impronta imprescindible para cualquier actividad que se pretenda emprender en el plano profesional.

Cualquier sector de las profesiones jurídicas exige una sólida formación general, un conocimiento "humanístico" del Derecho, un inconformismo crítico con el Derecho positivo y una intuición que permita adivinar el deber ser al que se oriente nuestra labor, acentuándose más en una época en que la ética social está en crisis, y donde la sociedad demanda que las profesiones más relacionadas con ella regeneren y acentúen la condicionante ética necesaria en toda comunidad como factor de coordinación de nuestra común y pacífica convivencia.

La ciencia jurídica y su enseñanza dan un vuelco radical en la época contemporánea ${ }^{27}$, entre otros: Quintana -1836-, Espartero-1842-, Pidal-1841-, o por ejemplo, Gamazo -1883-; siendo muchas las reformas de los planes de estudios en la Facultad de Derecho en el siglo XX: Plan de 1931, de 1944, y de 1953 donde los saberes jurídicos han girado en torno a las tradicionales Áreas de Conocimiento ${ }^{28}$ :

\footnotetext{
${ }^{26}$ Imprescindible: ARIAS DE SAAVEDRA, I., El Plan de Estudios de la Universidad de Granada en 1776, Granada, 1996.

${ }^{27}$ Son fundamentales, entre otros especialistas de la materia, los estudios de PESET REIG, M., a título de ejemplo, pues son de sobra conocidos: "La enseñanza del Derecho y la legislación sobre Universidades durante el reinado de Fernando VII (1808-1833)", Anuario de Historia del Derecho Español 38 (1968), págs. 229-375, "Universidades y enseñanza del Derecho durante las regencias de Isabel II (1833-1843)", AHDE 39 (1969), págs. 481-544, o "El Plan Pidal de 1845 y la enseñanza en las Facultades de Derecho", AHDE 40 (1970), págs. 613-652.

28 Al respecto, entre otros: MARTÍNEZ NEIRA, M., La creación del cuerpo de catedráticos de universidad (1812-1857): estudio histórico-jurídico, Madrid, Universidad Carlos III de Madrid, 2013, y, MARTÍNEZ NEIRA, M., PUYOL MONTERO, J. M. a, y RODRÍGUEZ LÓPEZ, C., La Universidad española, 1889-1939. Repertorio de legislación, Madrid, 2004 (disponible digitalmente: http://e-
} 


\section{Doctrina y Jurisprudencia}

Derecho Romano, Derecho Canónico, Economía, Derecho Político, Derecho Administrativo, Derecho Financiero y Tributario, Derecho Internacional Público y Derecho Internacional Privado, Derecho Procesal, Derecho Penal, Derecho Civil, Derecho Mercantil, Filosofía del Derecho, Historia General del Derecho, y más tarde en la década de los sesenta, el Derecho del Trabajo ${ }^{29}$.

Todas ellas completadas, durante el siglo XIX y XX, con otras disciplinas, cuya finalidad era complementar la necesaria formación humanística del jurista: Literatura griega y latina, Filosofía, Oratoria forense, Historia Política y Social de España, Literatura general y española, Metafísica, etc... ${ }^{30}$.

\subsection{Proyecto sobre reforma de los Estudios de la Facultad de Derecho de} 1883.

De 1883 es el Proyecto sobre reforma de los Estudios de la Facultad de Derecho presentado por Felipe Sánchez Román al Ministro de Fomento, por encargo del mismo, en el que será decisiva la participación de Rafael de Ureña y Smenjaud, Catedrático de la Facultad de Derecho de Granada ${ }^{31}$, y que será la base del Plan de Estudios de 1953, vigente en la mayoría de las Universidades españolas hasta hace relativamente poco tiempo.

Dicho Proyecto fue ideado por el clima de insatisfacción general relativo a la enseñanza del Derecho en las Facultades de todo el país, cuya necesidad de reforma era evidente y una petición comúnmente aceptada por todos ${ }^{32}$.

archivo.uc3m.es/bitstream/handle/10016/7884/11_universidad_espanola.pdf;jsessionid=6C7863E504964 A88F3F1F600BF102C1C?sequence=1, consulta de 22 de octubre de 2016).

${ }^{29}$ MARÍA E IZQUIERDO, M. J. J. "Las primeras cátedras de derecho laboral en la universidad española", Cuadernos del Instituto Antonio de Nebrija de Estudios sobre la Universidad 10-1 (2007), págs. 251-267.

${ }^{30}$ BERMEJO CASTRILlO, M. Á. (Ed.), Manuales y textos de enseñanza en la Universidad liberal. VII Congreso Internacional sobre la Historia de las Universidades hispánicas, Madrid, 2004 (disponible digitalmente: http://orff.uc3m.es/bitstream/handle/10016/7886/13_manuales_y_textos.pdf?sequence=1).

${ }^{31}$ SÁNCHEZ ROMÁN, F. y UREÑA Y SMENJAUD, R., Proyecto sobre reforma de los estudios de la Facultad de Derecho, Madrid, Imprenta de la Revista de la Legislación, 1883 [también, en Revista General de Legislación y Jurisprudencia, tomo 63 (1883), págs. 350-379].

${ }^{32}$ GINER DE LOS RÍOS, F., Escritos sobre la universidad española. Antología (1893-1904), disponible digitalmente: $\quad$ http://www.cervantesvirtual.com/obra-visor/escritos-sobre-la-universidad-espanolaantologia-18931904--0/html/feec1346-82b1-11df-acc7-002185ce6064_1.html (consulta de 22 de octubre de 2016): "La Facultad que en los últimos tiempos ha entrado menos por el camino de la renovación del espíritu y los métodos científicos, es la de Derecho". 
La finalidad que dicho Plan de reforma perseguía era "la creación del tipo ideal del Jurisconsulto, que contiene las manifestaciones del Abogado, del Publicista, del Profesor de Derecho, del Juez y del Magistrado y aún del Estadista y del Legislador mismo y es generadora de todas ellas", defendiendo los autores del Proyecto como una necesidad el "reconstruir la unidad técnica en lo jurídico".

Así, la reforma propuesta por Sánchez Román y Ureña se concreta en tres puntos básicos de actuación que suponen una reforma completa para la unificación de los estudios de la Licenciatura en Derecho, incorporando asimismo las nuevas metodologías investigadoras y docentes en la Facultad:

- En primer lugar: refundir todas las enseñanzas jurídicas en una sola Facultad (las dos Secciones de Civil y Canónico y de Administrativo, carecen de relevancia en el orden práctico y hacen incompleta la formación de los titulados respectivos), junto a la incorporación de los estudios de Notariado a esta nueva Licenciatura única, para evitar dobles e incompletas enseñanzas y así procurar coordinar la formación de los distintos profesionales del mundo jurídico.

- En segundo lugar: suprimir las asignaturas del llamado año preparatorio, pues se concede excesivo peso a disciplinas que no son jurídicas, que deben

TORRES CAMPOS, M., "Discurso del Dr. D. Manuel Torres Campos en la Sesión Inaugural del curso de 1890 á 91", Anuario de la Academia de Derecho de la Universidad de Granada en 1890, Granada, 1890, págs. 25-43 (disponible digitalmente: file:///C:/Users/Usuario/Downloads/C036046-18.pdf, consulta de 22 de octubre de 2016), esp. pág. 38: “Al proponernos hacer un examen crítico de los planes últimamente adoptados, debemos notar que no se encuentran sus principales defectos en la elección de asignaturas ni en su distribución en años, sino en el régimen mismo de la enseñanza, de carácter casi exclusivamente teórico. El Profesor tiene que limitarse en la Cátedra a hacer discursos, de que ninguna utilidad sacan por lo común los alumnos, o a preguntar las lecciones que en los diferentes días se señalan, como medio de conocer lo que se estudia y de que se fije en la memoria. El alumno, que, dado el sistema de exámenes, sólo trata de hacer lúcidos ejercicios, que le hagan merecedor de buena nota, busca con preferencia libros de texto o apuntes, concediendo por lo general poca importancia a la asistencia a las clases. Y verdaderamente, el que tiene capacidad para entender los libros o apuntes, sin necesidad de profesor, aprovecha el tiempo, dejando de frecuentar la Universidad, con lo que consigue, en virtud de la libertad de enseñanza, hacer su carrera en tres o cuatro años, en lugar de los seis que la distribución normal establece. Un régimen de enseñanza que, haciendo inútil al Profesor, coloca en mejor lugar al alumno libre que al oficial, está indudablemente desacertado”. También al respecto, TORRES CAMPOS, M., "La reforma de los estudios jurídicos", Revista de los Tribunales, Tomo I (1878), págs. 393-410 y 457-470.

Para todo ello, VILLASEÑOR RODRÍGUEZ, I., "La cátedra de bibliografía jurídica de la Universidad Central de Madrid (1883-1936)", Revista General de Información y Documentación 16-2 (2006), págs. 65-91, disponible digitalmente: file:///C:/Users/Usuario/Downloads/10422-10503-1-PB.PDF (consulta de 22 de octubre de 2016). 


\section{Revista Internacional de \\ Doctrina y Jurisprudencia}

considerarse cubiertas por medio de la enseñanza del Bachiller, como medio de preparación precedente (de las quince asignaturas a cursar, seis no son jurídicas y ostentan demasiado peso en el Plan de Estudios: tres cursos de Literatura y dos de Historia Universal, yendo en detrimento de otras disciplinas jurídicas como la propia Historia del Derecho Español y el Derecho Procesal, por poner un ejemplo gráfico).

- Y en tercer lugar: procurar una más completa y acertada distribución de las enseñanzas jurídicas atendiendo a su peso real en la actividad práctica y en el contexto legal. El peso del Derecho positivo se hacía así patente, y la especialización y la necesidad de la formación práctica van a incidir directamente en la creación de nuevas asignaturas y en el cambio de protagonismo de otras.

\subsection{El Plan de Estudios de 1953.}

Dicha reforma, necesaria en los estudios jurídicos, con matices importantes respecto del Proyecto anteriormente analizado ${ }^{33}$, se convertirá en una realidad con la aprobación del Plan de Estudios de la carrera de Derecho de 1953, aprobado en virtud de Decreto de 1 de agosto de 1953:

“Artículo décimo. Las enseñanzas del periodo de Licenciatura de la Facultad de Derecho se dividirán en cinco cursos:

CURSO PRIMERO. Derecho natural. Historia e Instituciones del Derecho romano. Historia del Derecho. Derecho político.- Prácticas de lectura de textos jurídicos clásicos (latinos y españoles).

CURSO SEGUNDO. Derecho político. Derecho canónico. Derecho civil (parte general). Derecho penal (parte general). Economía política.

CURSO TERCERO. Derecho administrativo. Derecho civil (obligaciones y contratos). Derecho internacional público. Derecho penal (parte especial). Hacienda pública.

\footnotetext{
${ }^{33}$ MARTÍNEZ TRUJILLO, A., La Universidad de Granada (1900-1931), tesis doctoral, Granada, 1986: file://C:/Users/Usuario/Downloads/la-universidad-de-granada-19001931--0.pdf (consulta de 21 de octubre de 2016).
} 
CURSO CUARTO. Derecho administrativo (parte especial). Derecho del trabajo. Derecho civil (derechos reales e hipotecario). Hacienda pública (con especial atención al Derecho fiscal). Derecho procesal. Derecho mercantil.

CURSO QUINTO. Derecho civil (familia y sucesiones). Derecho procesal. Derecho mercantil. Derecho internacional privado. Filosofía del Derecho"34.

El Plan (antiguo) de 1953 se constituirá, por tanto, como el más longevo de la Facultad de Derecho de Granada ${ }^{35}$, en vigor hasta el curso académico 1999-2000 (al margen de su progresiva eliminación), con la inclusión "ocasional” de alguna asignatura "optativa", aunque fundamental, como las Instituciones de Derecho Comunitario (Acción Jean Monnet); luego llegarían otras asignaturas optativas: Historia del Derecho Privado, Proceso Administrativo, Documentos y acción notarial en el Derecho privado, Las nuevas formas de religiosidad, Derecho de excepción, La suspensión colectiva e individual de derechos y libertades en la Constitución de 1978, y Documentación aplicada a las Ciencias Jurídicas.

La llegada de la Ley General de Educación y financiación de la Reforma educativa, promulgada el 4 de agosto de $1970^{36}$, dispondrá tres aspectos básicos y fundamentales:

\footnotetext{
${ }^{34}$ DECRETO de 11 de agosto de 1953 por el que se establecen los planes de estudios de las Facultades de Filosofía y Letras, Ciencias, Derecho, Medicina, Veterinaria y Ciencias Políticas, Económicas y Comerciales, en Boletín Oficial del Estado núm. 241, de 29 de agosto de 1953, págs. 5185 a 5190 : https://www.boe.es/datos/pdfs/BOE//1953/241/A05185-05190.pdf (consulta de 20 de octubre de 2016):
}

\footnotetext{
"Artículo undécimo. Las Facultades de Derecho organizarán un curso de Sociología con especial referencia a los problemas jurídicos, que habrá de seguirse con carácter obligatorio. pero pudiendo elegir los alumnos el cursarlo en cualquiera de los años comprendidos entre el segundo y el quinto, ambos inclusive. Las Facultades organizarán igualmente cursos prácticos de Contabilidad, de interés habitual para el ejercicio de la profesión de Abogado. Estas prácticas de Contabilidad no serán obligatorias, pero a los alumnos que las sigan con aprovechamiento se les expedirá un certificado o diploma de suficiencia en las mismas".

${ }^{35}$ CAMACHO EVANGELISTA, F., "La Universidad de Granada en el siglo XX", IDEAL, 9 de mayo 1977. PUY MUÑOZ, F., La Facultad de Derecho de Granada entre 1953 y 1958, Santiago de Compostela, 2008. MOTOS GUIRAO, M., La Facultad de Derecho de Granada: de ayer a hoy (Conferencia pronunciada en la celebración de San Raymundo de Peñafort el 23.I.1981), Granada, 1988.

${ }^{36}$ BOE, núm. 187, de 6 de agosto de 1970: https://www.boe.es/boe/dias/1970/08/06/pdfs/A1252512546.pdf (consulta de 15 de octubre de 2016).
}

Artículo 70 de la Ley General de Educación, "La educación universitaria tiene por finalidad:

1. ${ }^{\circ}$ Completar la formación integral de la juventud, preparar a los profesionales que requiera el país y atender al perfeccionamiento en el ejercicio de los mismos ... 
- Configuración de la enseñanza en tres ciclos.

- Reforzamiento de los Departamentos como unidades de enseñanza e investigación.

- Autonomía: para que puedan determinar por sí mismas los procedimientos de control y verificación de conocimientos, el cuadro y el sistema de sus enseñanzas y su régimen de docencia e investigación dentro de las disposiciones de la presente Ley y de las normas que se dicten para su desarrollo ${ }^{37}$.

A partir de aquí, y mediante Estatuto provisional, cada Universidad deberá regular su régimen de actividad y su autonomía; se establecía así, la Universidad española con personalidad jurídica, patrimonio propio y plena capacidad de gestión, aprobándose en lo que nos afecta, los Estatutos provisionales de la UGR, en Junta de Gobierno el 28 de septiembre de $1970^{38}$.

Con la promulgación de la Constitución española de 1978 se iniciará una etapa, artículo 27.10 Constitución 1978:

«Se reconoce la autonomía de las Universidades, en los términos que la Ley establezca».

Iniciándose, como indica Merchán, un cambio "muy rupturista y profundo" en la estructura y "realidad" universitaria de nuestro país 39.

2. ${ }^{\circ}$ Fomentar el progreso cultural, desarrollar la investigación en todos los niveles con libre objetividad y formar a científicos y educadores.

3. ${ }^{\circ}$ Contribuir al perfeccionamiento del sistema educativo nacional, así como al desarrollo social y económico del país."

${ }^{37}$ MARTÍNEZ DHIER, A., y PRADOS GARCÍA, C. (Coord.), Historia de las Universidades durante la transición política española (1968-1983), Granada, 2016.

38 DECRETO 1236/1971, de 14 de mayo, por el que se aprueban los Estatutos provisionales de la Universidad de Granada, en BOE, núm. 144, de 17 de junio de 1971, disponible digitalmente en: https://www.boe.es/boe/dias/1971/06/17/pdfs/A09775-09784.pdf (consulta de 22 de octubre de 2016):

“Artículo 1. La Universidad de Granada, Centro estatal, es una institución de derecho público, con personalidad jurídica y patrimonio propio. Goza de toda la autonomía que determina la Ley General de Educación y demás disposiciones legales vigentes en el plano académico, administrativo, económico, financiero y presupuestario y que se concreta en estos Estatutos".

${ }^{39}$ MERCHÁN ÁlVAREZ, A., Documentos históricos de la Universidad de Sevilla (II). Los Estatutos de Autonomía del siglo XX, Sevilla, 2005, esp. pág. 11. 


\section{Doctrina y Jurisprudencia}

En este sentido, el Claustro de la Facultad de Derecho granadina, en sus sesiones de 12, 18, 19 de enero, y 16 de marzo de 1979, aprobó el "Estatuto de la Facultad de Derecho", en cuyo artículo 1.1 se determina que:

"La Facultad de Derecho de la Universidad de Granada tiene como fin primordial la enseñanza, investigación y estudio de los saberes jurídicos y sociales al servicio de la justicia, libertad e igualdad, bajo el principio de autonomía y con la participación activa y responsables de todos sus miembros. Al mismo tiempo la Facultad de Derecho deberá cumplir también la función de extensión universitaria con la difusión y ofrecimiento de sus conocimientos al inmediato contexto social" ${ }^{\text {" }}$.

La L.O. para la Reforma de la Universidad 11/1983, de 25 de agosto $^{41}$, señala en su artículo 3, un modelo diferente, pues contempla la Universidad como institución a modo de comunidad, que cumple como función el servicio público de la educación superior, en régimen de autonomía ${ }^{42}$. Dos cuestiones fundamentales:

1.- Autonomía de gobierno (órganos unipersonales y colegiados), es decir, determinar quienes mandan o tienen poder de decisión en la Universidad, tanto en el ámbito unipersonal como colegiado.

40 Estatuto de la Facultad de Derecho, Granada, Universidad de Granada, Tip. Ntra. Sra. de las Angustias, marzo, 1979.

41 BOE núm. 209, de 1 de septiembre de 1983, págs. 24034-24042: https://www.boe.es/boe/dias/1983/09/01/pdfs/A24034-24042.pdf (consulta de 18 de octubre de 2016): “... la Constitución española ha venido a revisar el tradicional régimen jurídico administrativo centralista de la Universidad española, al reconocer en el número 10 de su artículo 27 la autonomía de las Universidades".

Artículo 1: "Uno. El servicio público de la educación superior corresponde a la Universidad, que lo realiza mediante la docencia, el estudio y la investigación.

Dos. Son funciones de la Universidad al servicio de la sociedad:

La creación, desarrollo, transmisión y crítica de la ciencia, de la técnica y de la cultura.

La preparación para el ejercicio de actividades profesionales que exijan la aplicación de conocimientos y métodos científicos o para la creación artística.

El apoyo científico y técnico al desarrollo cultural, social y económico tanto nacional como de las Comunidades Autónomas."

42 Para la autonomía de la Universidad "actual”, es interesantísimo, el estudio de CÁMARA VILLAR, G., "La autonomía universitaria en España hoy, entre el mito y la realidad", Revista catalana de Dret públic 44 (2012), págs. 67-109 (http://revistes.eapc.gencat.cat/index.php/rcdp/article/view/2239/n44-camaraes.pdf, consulta de 23 de octubre de 2016). 


\section{Doctrina y Jurisprudencia}

2.- Autonomía normativa (Estatutos y otras normas), auto dictarse normas en el ejercicio de dicho autogobierno, tanto de índole fundamental, es el caso de los Estatutos, carta constitucional de la Universidad, como secundarias o de funcionamiento interno ${ }^{43}$ :

“Artículo tercero:

1. Las Universidades están dotadas de personalidad jurídica y desarrollan sus funciones en régimen de autonomía y de coordinación entre todas ellas.

2. En los términos de la presente Ley, la autonomía de las Universidades comprende:

a) La elaboración de los Estatutos y demás normas de funcionamiento interno.

b) La elección, designación y remoci6n de los órganos de gobierno y administración.

c) La elaboración, aprobación y gestión de sus presupuestos y la administración de sus bienes.

d) El establecimiento y modificación de sus plantillas.

e) La selección, formación y promoción del personal docente e investigador y de administración y servicios, así como la determinación de las condiciones en que ha de desarrollar sus actividades.

f) La elaboración y aprobación de planes de estudio e investigación.

g) La creación de estructuras específicas que actúen como soporte de la investigación y la docencia.

h) La admisión, régimen de permanencia y verificación de conocimientos de los estudiantes.

i) La expedición de sus títulos y diplomas.

\footnotetext{
${ }^{43}$ MARTÍNEZ DHIER, A. y PRADOS GARCÍA, C. (Editores), Historia de las Universidades durante el proceso de democratización española (1968-1983). Una perspectiva jurídica. Madrid, Editorial Dykinson, 2016 (en prensa).
} 
j) El establecimiento de relaciones con otras instituciones académicas, culturales o científicas, españolas o extranjeras.

k) Cualquier otra competencia necesaria para el adecuado cumplimiento de las funciones señaladas en el artículo 1 de la presente Ley".

Debemos señalar que en 1993 la Universidad de Granada dejará de contar con los Campus Universitarios de Jaén ${ }^{44}$ y Almería ${ }^{45}$, aunque seguirá contando, como en la actualidad, con los de Ceuta y Melilla ${ }^{46}$.

\subsection{El Plan de Estudios de 2000.}

Desde el curso académico 2000-2001, y hasta septiembre de 2010 se implantó el nuevo Plan de Estudios de la Licenciatura en Derecho ${ }^{47}$, al margen de la puesta en marcha de las dobles titulaciones (Derecho-Administración y Dirección de Empresas y

\footnotetext{
44 “LEY 5/1993, de 1 de julio, de creación de la Universidad de Jaén”, en BOE núm. 203, de 25 de agosto de 1993, págs. 25673-25677 (https://www.boe.es/boe/dias/1993/08/25/pdfs/A25673-25677.pdf): "La nueva Universidad se justifica históricamente en la existencia en el siglo XVI del Estudio General de Santa Catalina, que en 1629 llegó a ser Universidad Pontificia por bula de Bonifacio VIII, cuestión que nunca ha dejado de estar presente en la memoria colectiva del ciudadano de Jaén. La tradición universitaria de Jaén no se ha limitado sólo al citado caso; conviene añadir la existencia desde el siglo XVI y hasta inicio del siglo XIX de la Universidad de Baeza, hoy considerada en la Ley de Coordinación del Sistema Universitario de Andalucía como una de las sedes de la futura Universidad Internacional de Andalucía".
}

45 “LEY 3/1993, de 1 de julio, de creación de la Universidad de Almería", BOE núm. 202, de 24 de agosto de 1993, págs. 25586-25590 (http://www.boe.es/boe/dias/1993/08/24/pdfs/A25586-25590.pdf).

${ }^{46}$ En el Campus Universitario de Melilla se implantará, en el curso académico 2014-2015, por primera vez en la historia de la institución granadina, los estudios jurídicos, con el inicio del doble Grado Derecho-ADE.

47 “RESOLUCIÓN de 1 de septiembre de 1999, de la Universidad de Granada, por la que se hace público el plan de estudios de Licenciado en Derecho que se impartirá en la Facultad de Derecho, dependiente de esta Universidad", en BOE núm. 7, de 8 de enero de 2000, págs. 835-848: http://www.boe.es/boe/dias/2000/01/08/pdfs/A00835-00848.pdf (consulta de 15 de octubre de 2016). Aprobado por la Universidad el plan de estudios de Licenciado en Derecho, que se impartirá en la Facultad de Derecho, de conformidad con lo dispuesto en el Real Decreto 1424/1990, de 26 de octubre, por el que se establece el título oficial de Licenciado en Derecho y las directrices generales propias de los planes de estudios conducentes a la obtención de aquél («Boletín Oficial del Estado» número 278, de 20 noviembre); en los artículos 28 y 29 de la Ley Orgánica 11/1983, de 25 de agosto, de Reforma Universitaria («Boletín Oficial del Estado» número 209, de 1 de septiembre); 225 y concordantes de los Estatutos de dicha Universidad, publicados por Decreto 162/1985, de 17 de julio («Boletín Oficial del Estado» número 55, de 5 de marzo de 1986), y en cumplimiento de lo señalado en el artículo 10.2 del Real Decreto 1497/1987, de 27 de noviembre, sobre directrices generales comunes de los planes de estudios de los títulos de carácter oficial y validez en todo el territorio nacional («Boletín Oficial del Estado» número 298, de 14 de diciembre), y en el Real Decreto 1267/1994, de 10 de junio, por el que se modifica el anterior («Boletín Oficial del Estado» número 139, de 11 de junio). 


\section{Doctrina y Jurisprudencia}

Derecho-Ciencias Políticas y de la Administración ${ }^{48}$ ), con la incorporación de los créditos europeos (E.C.T.S.), y las asignaturas "troncales", "optativas" y la "libre configuración específica", prueba evidente de un paso más hacia la unidad e integración de Europa, donde han tenido un papel primordial los estudiantes universitarios, que siguiendo a Gibert, no son "los clientes, los adquirentes, los espectadores, los pasajeros de la ciencia, sino precisamente sus titulares, sus actores, y que su obligación actual de aprender es sólo un medio y una etapa, que les permitirá hacer, de algún modo, una ciencia superior a la aprendida"49, puesto que es en su etapa de alumno universitario, cuando el jurista analiza y estudia la norma sin estar condicionado por una inmediata aplicación interesada al caso concreto que se le plantea; cuando los principios, las instituciones y las técnicas jurídicas, pueden ser comprendidos serenamente en todo su alcance y finalidad, adquiriéndose una cosmovisión del ordenamiento jurídico, como estructura necesariamente armónica, con sus reglas y mecanismos de funcionamiento ${ }^{50}$.

\subsection{El Grado en Derecho: ¿E.E.E.S.?}

La Ley Orgánica 6/2001, de 21 de diciembre, de Universidades, en su nueva redacción dada por la Ley Orgánica 4/2007, de 12 de abril, por la que se modifica la anterior, define la estructura de las enseñanzas universitarias en tres ciclos: Grado, y Posgrado: Máster y Doctorado ${ }^{51}$.

\footnotetext{
${ }^{48}$ Por un convenio entre la Facultad de Derecho y la de Ciencias Económicas y Empresariales, y de la Facultad de Derecho y la de Ciencias Políticas y Sociología.

${ }^{49}$ GIBERT, R., "Eduardo de Hinojosa y la Historia del Derecho", Boletín de la Universidad de Granada 24 (1952), págs. 194-209.

50 GIBERT Y SÁNCHEZ DE LA VEGA, R., "Discurso conmemorativo del 25 aniversario de la promoción 1952-1957 de la Facultad de Derecho de la Universidad de Granada", Revista de la Facultad de Derecho de la Universidad de Granada 6 (2003), págs. 527-533.

51 "LEY ORGÁNICA 4/2007, de 12 de abril, por la que se modifica la Ley Orgánica 6/2001, de 21 de diciembre, de Universidades", en BOE núm. 89, de 13 de abril de 2007, págs. 16241-16260: https://www.boe.es/boe/dias/2007/04/13/pdfs/A16241-16260.pdf (consulta de 16 de octubre de 2016): “... La Ley apuesta decididamente por la armonización de los sistemas educativos superiores en el marco del espacio europeo de educación superior y asume la necesidad de una profunda reforma en la estructura y organización de las enseñanzas, basada en tres ciclos: Grado, Máster y Doctorado. Se da así respuesta al deseo de la comunidad universitaria de asentar los principios de un espacio común, basado en la movilidad, el reconocimiento de titulaciones y la formación a lo largo de la vida. El nuevo modelo de enseñanzas aporta una manera diferente de entender la universidad y sus relaciones con la sociedad. Se trata de ofrecer una formación de calidad que atienda a los retos y desafíos del conocimiento y dé respuesta a las necesidades de la sociedad...".
} 
A partir del curso académico 2010-2011 se pondrá en marcha el Grado en Derecho $^{52}$, el nuevo Plan de Estudios en la actualidad vigente, junto a los dobles Grados (Derecho-Administración y Dirección de Empresas y Derecho-Ciencias Políticas y de la Administración), provocando un vuelco (aunque hay quien lo denomina "innovación") en el proceso educativo, pues del proceso tradicional de "enseñanza" se pasará al proceso de "aprendizaje" donde los discentes se convierten en los auténticos artífices y forjadores del sistema educativo universitario (¡que Dios nos pille confesados!), y que conllevará, lógicamente, la progresiva desaparición de los estudios de la Licenciatura en Derecho (Plan de Estudios 2000) y de las diversas asignaturas, troncales, optativas y de libre configuración, en las que se sustentaba ${ }^{53}$.

En el curso académico 2012-2013 entró en juego una nueva titulación: el Grado en Criminología ${ }^{54}$, cuya implantación ha venido a aumentar considerablemente la oferta académica de nuestra Facultad de Derecho, dando así respuesta a una demanda social sentida, por ejemplo, desde la "Conferencia de las instituciones especializadas y de las Organizaciones Internacionales no gubernamentales interesadas en la prevención del delito y en el tratamiento de los delincuentes", reunida en Ginebra el 17 de diciembre de

\footnotetext{
52 "RESOLUCIÓN de 4 de febrero de 2011, de la Universidad de Granada, por la que se publica el plan de estudios de Graduado en Derecho", en BOE núm. 43, de 19 de febrero de 2011, págs. 19531-19533: https://www.boe.es/boe/dias/2011/02/19/pdfs/BOE-A-2011-3310.pdf (consulta de 17 de octubre de 2016).

${ }^{53}$ La titulación de Graduado o Graduada en Derecho por la Universidad de Granada, ha obtenido el Informe favorable, en el proceso de renovación de la acreditación del título, por parte de la Agencia Andaluza del Conocimiento, dependiente de la Consejería de Economía y Conocimiento de la Junta de Andalucía (conforme a lo dispuesto en el artículo 27 bis del Real Decreto 1393/2001, de 29 de octubre, por el que se establece la ordenación de las enseñanzas universitarias oficiales, y según los criterios señalados por la Guía para la renovación de la acreditación de los títulos universitarios de grado y máster de Andalucía, de la Dirección de Evaluación y Acreditación de la Agencia Andaluza del Conocimiento, diciembre de 2014). Informe final disponible digitalmente: http://grados.ugr.es/derecho/static/CMSRemoteManagement/*/vic_cal/_dir_remotos/base_grado/_list_/au toinformes-e-informes-de-seguimiento
}

"REAL DECRETO 1393/2001, de 29 de octubre, por el que se establece la ordenación de las enseñanzas universitarias oficiales" (última modificación de 3 de junio de 2016), BOE núm. 260, de 30 de octubre de 2007, disponible en: https://www.boe.es/buscar/pdf/2007/BOE-A-2007-18770-consolidado.pdf

54 "RESOLUCIÓN de 4 de junio de 2013, de la Universidad de Granada, por la que se publica el plan de estudios de Graduado en Criminología”, en BOE núm. 147, de 20 de junio de 2013, págs. 46649-46651: http://boe.es/boe/dias/2013/06/20/pdfs/BOE-A-2013-6731.pdf (consulta de 17 de octubre de 2016). 
1952, bajo los auspicios de la O.N.U., que recomendaba la puesta en marcha de los estudios universitarios en Criminología ${ }^{55}$.

\section{Protagonistas en la Historia de la facultad de Derecho de}

\section{GRANADA: LOS JURISTAS.}

Es larga y cuantiosa la nómina de ilustres profesores y juristas, en el más amplio sentido de la expresión, que han pasado por aquellas aulas, sean como discentes, sean como docentes, referente en los estudios jurídicos de España, que incluso han traspasado nuestras fronteras; algunos de los nombres más relevantes de la ciencia jurídica y de la cultura, en general, de nuestro país, desde Francisco Bermúdez de Pedraza hasta, entre otros ${ }^{56}$ :

- Manuel Seijas Lozano: Abogado, Diputado, Senador, Fiscal del Tribunal Supremo de Justicia, Académico, Ministro de varias carteras, autor e impulsor del

\footnotetext{
${ }^{55}$ El DECRETO 182/1990, de 5 de junio, de la Consejería de Educación y Ciencia, B.O.J.A. núm. 98 de 27 de noviembre, aprueba su Reglamento; hoy en día, el Instituto Andaluz Interuniversitario de Criminología, es un centro universitario de investigación científica, técnica y de especialización, de acuerdo con lo dispuesto en al artículo 10 de la Ley Orgánica 6/2001, de 21 de diciembre, de Universidades (http://criminol.ugr.es/web/). Desde 1990 la Sección de Granada del Instituto Andaluz Interuniversitario de Criminología ha venido supliendo, en parte, esta carencia, desarrollando una prolífica actividad docente e investigadora, recogiendo ahora el testigo el nuevo Grado, cuyo objetivo general es "la formación de profesionales que cubran la necesidad que tiene la sociedad en relación a la prevención y control del crimen y/o comportamiento desviado", y cuyo objetivo final es "formar profesionales preparados para asumir las responsabilidades en el extenso campo de la Administración de justicia y de la seguridad pública o privada", proporcionando a los estudiantes una formación interdisciplinar, integrada por conocimientos dirigidos a desarrollar habilidades y competencias psicosociales, criminológicas, jurídicas y científicas que habiliten tanto para el ejercicio profesional como para el desarrollo de la investigación aplicada.

${ }^{56}$ Para todos ellos, son imprescindibles, entre otros muchos: PELÁEZ ALBENDEA, M. (Ed. y Coord.), Diccionario Crítico de Juristas Españoles, Portugueses y Latinoamericanos (Hispánicos, Brasileños, Quebequenses y restantes francófonos). Vol. I (A-L) [hasta 2005], Zaragoza-Barcelona, 2005, Diccionario Crítico de Juristas Españoles, Portugueses y Latinoamericanos (Hispánicos, Brasileños, Quebequenses y restantes francófonos), [hasta noviembre 2006], Vol. II. $1^{\circ}$ (M-Va), Zaragoza-Barcelona, 2006, Diccionario Crítico de Juristas Españoles, Portugueses y Latinoamericanos (Hispánicos, Brasileños, Quebequenses y restantes francófonos), [hasta abril 2008], Vol. II. (M-Z) $2^{\circ}$ (Ve-Z). Apéndice Biográfico $\psi$ (A-Z), Zaragoza-Barcelona, 2008, y Diccionario Crítico de Juristas Españoles, Portugueses y Latinoamericanos (Hispánicos, Brasileños, Quebequenses y restantes francófonos). Apéndice biográfico $q$, $\alpha$ [hasta junio de 2012] de los Apéndices $\Psi$ y $\Phi, \alpha$ y $\beta$ de los 2600 juristas [A-Z] Vol. III (= tomo $4^{\circ}$ de la colección), Zaragoza-Barcelona, 2012.
}

PETIT CALVO, C., Diccionario de Catedráticos españoles de Derecho (1847-1943): http://portal.uc3m.es/portal/page/portal/instituto_figuerola/programas/phu/diccionariodecatedraticos 


\section{Doctrina y Jurisprudencia}

Código penal de 1848, llevó a las Universidades la formación de los Notarios -Ley de 28 de noviembre de $1856{ }^{-57}$.

- José de Castro y Orozco: el «Marqués de Gerona»: Rector de nuestra Universidad, Abogado, Vocal de la Comisión General de Codificación, Presidente de Sala del T.S., Ministro, Académico y autor -entre otras- de la famosa Instrucción del Procedimiento Civil de 30 de septiembre de 1853.

- Nicolás Salmerón y Alonso: Presidente de la I República española y Catedrático de la Universidad de Madrid ${ }^{58}$.

- Eusebio Sánchez Reina: Abogado, Presidente del Ilustre Colegio de Abogados de Granada y primer Catedrático de Historia del Derecho de nuestra Universidad tras la implantación de la Cátedra por R. D. 1883.

- Juan Montilla y Adán: del Partido Liberal, Fiscal del Tribunal Supremo (11 de marzo de 1901) y Ministro de Gracia y Justicia - cargo en el que por su condición de Notario Mayor del Reino firmó el Acta de la mayoría de edad de Alfonso XIII-, autor de un interesantísimo Proyecto de Código penal de $1902^{59}$.

- Niceto Alcalá-Zamora y Torres: excelente alumno [todo matrículas de honor], Abogado, Académico y Presidente de la II República española ${ }^{60}$.

\footnotetext{
${ }^{57}$ Entre otros: MARTÍNEZ DHIER, A., El jurisconsulto granadino Manuel de Seijas (Hernández) Lozano, precursor de la Codificación en España. Prólogo de Juan Baró Pazos. Número I de la Colección "Juristas andaluces Ilustres", Córdoba, Diputación de Córdoba, CajaSur Publicaciones, Ilustre Sociedad Andaluza de Estudios Histórico-Jurídicos, 2009.
}

${ }^{58}$ Actas del Congreso "Nicolás Salmerón y Alonso. A propósito del centenario de la Unión Republicana de 1903”, Vicerrectorado de Extensión Universitaria de la Universidad de Almería, en colaboración con el CEP de Almería. Almería 2003. MARTÍNEZ DHIER, A., y SÁNCHEZ ARANDA, A., "Nicolás Salmerón, la ética de la razón sobre la pasión política", Revista de la Facultad de Derecho de la Universidad de Granada 6 (2003), págs. 569-577.

${ }^{59}$ LASSO GAITE, J. F., Crónica de la Codificación Española. 5. Codificación Penal, volumen I, Madrid, 1970, págs. 579-585: "Proyecto del Ministro Juan Montilla Adán”, esp. pág. 585: “El proyecto Montilla es francamente modernista. Tiene preceptos innovadores favorables a mitigar e individualizar la pena mediante la irresponsabilidad por defectos mentales, con referencia a epilépticos y sordomudos; la remisión a la jurisdicción especial de menores delincuentes; amplia la minoría hasta 23 años; sustitución de las atenuantes nominadas por una fórmula especial y supresión de las agravantes predeterminadas; desarrollo de la reincidencia; abolición de la pena de muerte y simplificación de las privativas de libertad; mayor arbitrio judicial, condena condicional para los primarios y retención indeterminada para los incorregibles".

60 MARTÍNEZ DHIER, A. y SÁNCHEZ ARANDA, A., "Niceto Alcalá Zamora, estudiante de la Facultad de Derecho de la Universidad de Granada", Revista de la Facultad de Derecho de la 
- Eduardo de Hinojosa y Naveros: destacado político, Catedrático de Historia

Medieval en la Universidad de Madrid -hoy en día Complutense-, y refundador de los estudios histórico-jurídicos en nuestro país, creador de una Escuela -o secuela- de historiadores del Derecho ${ }^{61}$.

- Nicolás de Paso y Delgado: Catedrático de Derecho Canónico, Ampliación de Derecho Civil Romano y español, y de Derecho Civil y Canónico, marchará a Madrid.

- Blas Infante Pérez de Vargas: realizó la Licenciatura en sólo un curso y medio, Notario, y padre de la pretendida "patria andaluza" -hoy en día sólo "realidad nacional" -62 .

- Rafael de Ureña y Smenjaud: llegado de Oviedo, donde ocupó las Cátedras de Derecho Político y Administrativo, fue catedrático en Granada de Disciplina general de la Iglesia y particular de España, Catedrático en comisión de Hacienda Pública, y de Derecho Político y Administrativo; posteriormente se trasladará a Madrid como Catedrático de Literatura Jurídica de Doctorado; son famosos sus estudios sobre Historia de la Literatura Jurídica española) ${ }^{63}$.

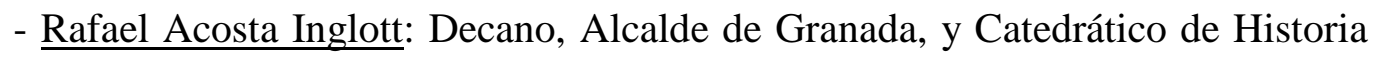
General del Derecho, y posteriormente de Derecho Romano ${ }^{64}$.

Universidad de Granada 6 (2003), págs. 561-567. SÁNCHEZ GARRIDO, A., Niceto Alcalá Zamora, de ilustre jurista a Jefe de Estado, Córdoba, 2015.

${ }^{61}$ MORENO CASADO, J., Eduardo de Hinojosa, estudiante, Granada, 1944 (separata). MARTÍNEZ DHIER, A., "150 años del nacimiento de Eduardo de Hinojosa y Naveros, historiador del Derecho", Revista de la Facultad de Derecho de la Universidad de Granada 6 (2003), págs. 549-559.

62 INIESTA COULlaUT-VALERA, E., Blas Infante, alumno de la Facultad de Derecho de la Universidad de Granada (1905-1906), Conferencia de 4 de diciembre de 1990, Granada, 1990. MARTÍNEZ DHIER, A., "A propósito de la reforma estatutaria en Andalucía: el ideario político de Blas Infante Pérez", en Codex, Boletín de la Ilustre Sociedad Andaluza de Estudios Histórico-Jurídicos 4 (2010), págs. 261-303.

${ }^{63}$ PETIT, C., "La prensa en la Universidad: Rafael de Ureña y la Revista de Ciencias jurídicas y sociales (1918-1936)", Quaderni Fiorentini per la Storia del Pensiero giuridico moderno 24 (1995), págs. 199302, y "El catedrático y la biblioteca. Visigotismo y profesión universitaria en Rafael de Ureña", en La legislación gótico-hispana (Leges antiquiores-Liber Iudiciorum).Estudio crítico, Pamplona, 2003. MARTÍNEZ DHIER, A., Rafael de Ureña y Smenjaud y sus Observaciones acerca del desenvolvimiento de los Estudios de Historia del Derecho Español. Cien años de la primera Historiografía Jurídica española (1906-2006), Granada, 2007.

64 ORDEN nombrando Decano de la Facultad de Derecho de la Universidad de Granada a D. Rafael Acosta Inglott, en Gaceta de Madrid núm. 182, de 30 de junio de 1936, pág. 2795: http://www.boe.es/datos/pdfs/BOE//1936/182/B02795-02795.pdf 


\section{Doctrina y Jurisprudencia}

- Felipe Sánchez Román [padre]: Senador, Catedrático de Derecho Civil, y

Fiscal del Tribunal Supremo, y coautor del Plan de 1883 para la reforma de las

Facultades de Derecho, visto antes, y autor de otro para la enseñanza, en general, en España.

- Faustino Álvarez del Manzano y Álvarez Rivera: Catedrático de Elementos de Derecho Mercantil y Penal.

- Felipe Clemente de Diego y Gutiérrez: Catedrático de Derecho Romano, luego de Derecho Civil.

- Andrés Manjón y Manjón: Catedrático de Derecho Canónico y fundador de las modelos Escuelas Pías del Ave María.

- Guillermo García Valdecasas y Paéz: venido de Salamanca y Barcelona, Catedrático de Derecho Civil ${ }^{65}$.

- Manuel Torres Campos: Catedrático de Derecho Internacional Público y Privado.

- José Manuel Segura Soriano: destacado republicano, Catedrático de Historia General del Derecho Español, magistrado de la Audiencia de Granada y secretario personal de Manuel de Falla.

- Fernando de los Ríos Urruti: Catedrático de Derecho Político español comparado con el extranjero, destacadísimo político, figura cumbre en la Historia de España, fallecido en Nueva York.

- Manuel Torres López: Catedrático de Historia General del Derecho, Decano y Alcalde que fue de Salamanca, luego Catedrático de Madrid.

- Alfonso García Valdecasas y García Valdecasas: Catedrático de Derecho Civil.

65 DECRETO nombrando Decano de la Facultad de Derecho de la Universidad de Granada a D. Guillermo García Valdecasas y Páez, en Gaceta de Madrid núm. 140, de 20 de mayo de 1931, pág. 819: http://www.boe.es/datos/pdfs/BOE//1931/140/A00819-00819.pdf

Como Decano Honorario de la Facultad de Derecho: ORDEN nombrando Decano de la Facultad de Derecho de la Universidad de Granada al Catedrático jubilado de la misma don Guillermo García Valdecasas y Páez, en Boletín Oficial del Estado núm. 325, de 21 de noviembre de 1939, págs. 65486549: http://www.boe.es/datos/pdfs/BOE//1939/325/A06548-06549.pdf 
- José Álvarez de Cienfuegos y Cobos: Catedrático de Economía Política y Hacienda Pública.

- Juan Ossorio Morales: finísimo jurista, Catedrático de Derecho Civil, Decano y Alcalde de Granada ${ }^{66}$.

- Enrique Gómez Arboleya: Catedrático de Filosofía del Derecho, primero en Sevilla, luego en Granada.

- Francisco Murillo Ferrol: Catedrático de Ciencia Política y Sociología, maestro de una larga saga de Profesores de Derecho Constitucional, Sociología y de Ciencia Política y de la Administración. Doctor honoris causa por la Universidad de Granada.

- Emilio Langle y Rubio: primero penalista y luego Catedrático de Derecho Mercantil.

- Antonio Mesa-Moles Segura: excelente Profesor, Catedrático de Derecho Administrativo.

- Leonardo Prieto Castro: Catedrático en Madrid de Derecho Procesal, creador de una Escuela.

- Carlos García Oviedo: Catedrático de Derecho Penal, luego en Sevilla.

- Álvaro d’Ors Pérez-Peix: Catedrático de Derecho Romano, durante un brevísimo periodo de tiempo, en nuestra Universidad, muy probablemente, prescindiendo de ideologías y creencias, uno de los mejores juristas españoles del siglo $\mathrm{XX}^{67}$.

- Juan del Rosal: Catedrático de Derecho Penal en Valladolid y Madrid.

- Juan José Ruiz-Rico López-Lendínez: Catedrático de Derecho Constitucional, creador de una Escuela, y Magistrado del Tribunal Superior de Justicia de Andalucía, Ceuta y Melilla.

\footnotetext{
${ }^{66}$ ORDEN por la que se nombra a don Juan Ossorio Morales, Decano de la Facultad de Derecho de la Universidad de Granada, en Boletín Oficial del Estado núm. 332, de 28 de noviembre de 1941, página 9288: http://www.boe.es/datos/pdfs/BOE//1941/332/A09288-09288.pdf

${ }^{67}$ MARTÍNEZ DHIER, A., “Álvaro d’Ors Pérez-Peix (1915-2004). Entre el Derecho Romano y la Historia del Derecho", Álvaro d'Ors. Homenaje a un Maestro, Santiago de Chile (Chile), 2004, pags. 1125 .
} 


\section{Doctrina y Jurisprudencia}

- Manuel de la Higuera Rojas: Decano y Catedrático de Derecho Romano.

- José María Stampa Braun: Catedrático de Derecho Penal, y afamado $\operatorname{abogado}^{68}$.

- Miguel Motos Guirao: Decano y Decano honorario, Catedrático de Derecho Mercantil.

- José Antonio Sainz Cantero: creador de una Escuela, Vicerrector y Catedrático de Derecho Penal.

- Juan Antonio Carrillo Salcedo: Catedrático de Derecho Internacional Público, medalla de nuestra Facultad, recientemente fallecido.

- José Cazorla Pérez: Catedrático de Derecho Político, Decano de la Facultad de Derecho, y primer Decano de la Facultad de Ciencias Políticas y Sociología de Granada.

- Antonio Gullón Ballesteros: Decano y Catedrático de Derecho Civil y Magistrado del Tribunal Supremo.

- Gil Carlos Rodríguez Iglesias: Presidente del Tribunal de Justicia de las Comunidades Europeas, Catedrático de Derecho Internacional Público, en la actualidad de la Universidad Complutense de Madrid, titular de la Cátedra Jean Monnet de Derecho Comunitario europeo, Director del Real Instituto Elcano de Estudios Internacionales y Estratégicos y "Doctor Honoris Causa" por la Universidad de Granada.

- Rafael Gibert y Sánchez de la Vega: Secretario General de la Universidad de Granada y Catedrático de Historia del Derecho, posteriormente en Madrid, y en la U.N.E.D., excelente historiador del Derecho.

- José Luis Santos Díez: Rector -y Rector Honorario- del Real Colegio Mayor de San Bartolomé y Santiago de la Universidad de Granada. Catedrático de Derecho Canónico de la Facultad de Derecho de la Universidad de Granada en el periodo 19671981. Luego marchará a Madrid, primero a la Universidad de Alcalá de Henares (19811985), la "Complutense histórica", y después a la Universidad Complutense de Madrid

68 MARTÍNEZ DHIER, A., "Notas para una biografía intelectual y académica de José María Stampa Braun (1925-2003), Catedrático de Derecho Penal y Abogado", Anuario de Derecho Penal y Ciencias Penales tomo 60 (2007), págs. 5-10. 


\section{Doctrina y Jurisprudencia}

(Segunda Cátedra: 1985-1989) en la que sería nombrado Profesor Emérito de Derecho Canónico y Derecho Eclesiástico del Estado, impartiendo docencia igualmente en la Universidad San Pablo-CEU.

- Eduardo Roca Roca: Catedrático de Derecho Administrativo, maestro de una auténtica Escuela de administrativistas, Gran Cruz de la Orden de San Raimundo de Peñafort, Académico numerario y Presidente de la Real Academia de Jurisprudencia y Legislación de Granada, Presidente del Instituto de Reales Academias de Andalucía y Profesor Emérito de la Universidad de Granada.

- Nicolás López Calera: Catedrático de Filosofía del Derecho, Profesor emérito de nuestra Universidad, y Decano de nuestra Facultad entre 1977 y 1980.

Por último, en esta breve reseña histórica, merecen destacarse los juristas que han ocupado el cargo de Rector de la Universidad de Granada en el siglo XX:

- Luis Sánchez Agesta: Rector de Granada (Decreto 28 de septiembre de $1951^{69}$ ), y Madrid, Catedrático de Derecho Político de las Universidades de Oviedo (1942), Granada (1942-1961) y Complutense de Madrid (1961-1984). Doctor honoris causa por las Universidades de Burdeos, de Mendoza y de Granada ${ }^{70}$. Presidente del Consejo Nacional de Educación, Senador por designación "real" (1977-1979), Académico de la Real Academia de Jurisprudencia y Legislación, y de la Real Academia de Ciencias Morales y Políticas. Premio Príncipe de Asturias de Ciencias Sociales (1998).

- José Vida Soria: Rector de la Universidad de Granada entre 1985 y 1989 (Decretos de 25 de abril de 1984 y de 24 de mayo de 1988). Catedrático de Derecho del Trabajo y de la Seguridad Social, Senador y Diputado, Profesor Emérito, Doctor honoris causa por la Universidad de Granada (30 de mayo de 2008) y uno de los redactores de la Constitución española de 1978. Medalla de Oro de la Universidad de Granada, Cruz de Honor de la Orden de San Raimundo de Peñafort al Mérito Jurídico y Medalla al Mérito Constitucional.

\footnotetext{
${ }^{69}$ DECRETO de 28 de septiembre de 1951 por el que se nombra para el cargo de Rector Magnífico de la Universidad de Granada a don Luis Sánchez Agesta, en Boletín Oficial del Estado núm. 285, de 12/10/1951, pág. 4610: http://www.boe.es/datos/pdfs/BOE//1951/285/A04610-04610.pdf

${ }^{70}$ Discurso disponible digitalmente: http://digibug.ugr.es/bitstream/10481/1173/1/15759805.pdf
} 


\section{Revista Internacional de \\ Doctrina y Jurisprudencia}

- Lorenzo Morillas Cueva: Rector de la Universidad de Granada entre 1992 y 2000 (Decretos de 21 de abril de 1992 y de 28 de mayo de 1996), y Presidente de la Conferencia de Rectores andaluces de 1995 a 1998. Catedrático de Derecho Penal, creador de una auténtica "escuela" de penalistas. Doctor honoris causa por las Universidades de San Petersburgo (2000), Lomas de Zamora (2000), Xalapa (2001), Almería (2013) y Jaén (2013). Sello conmemorativo del 280 Aniversario de la Universidad de La Habana. Medalla de Oro de nuestra Universidad, Cruz de Honor de la Orden de San Raimundo de Peñafort, Gran Cruz del Mérito Militar, con distintivo blanco, y Medalla UNICEF, concedida por United Nations Children's Fund. Actualmente ocupa el cargo de Director del Instituto Interuniversitario Andaluz de Criminología, con sede en Granada.

La lista es extensa, y merece un estudio reposado sobre los juristas protagonistas de la historia de la Facultad de Derecho de la Universidad de Granada y, en general, de la ciencia jurídica y de la historia de nuestro país. 